\title{
A DOR DA QUEIMADURA: TERRÍVEL PARA QUEM SENTE, ESTRESSANTE PARA QUEM CUIDA
}

\author{
Lídia Aparecida Rossi* \\ Cristina Camargo** \\ Clarinia M. N. M. Santos*** \\ Rita de Cássia de Paula Barruffin*** \\ Emília Campos de Carvalho****
}

ROSSI, L.A.; CAMARGO, C.; SANTOS, C.M.N.M.; BARRUFFIN, R.de C.de P.; CARVALHO, E.C.de. A dor da queimadura: terrível para quem sente, estressante para quem cuida. Rev.latino-am.enfermagem, Ribeirão Preto, v. 8, n. 3, p. 18-26, julho 2000.

Os objetivos deste foram identificar os significados culturais atribuidos pela equipe de enfermagem às manifestações de dor apresentadas pelos pacientes portadores de queimaduras e identificar as percepções dos pacientes frente à dor provocada pela queimadura e à assistência de enfermagem prestada nestas situações. Foram realizadas observações participantes e entrevistados quatro enfermeiros, cinco auxiliares e 12 pacientes, em uma unidade de queimados. A dor da queimadura foi compreendida pelos enfermeiros como: fisica e emocional. Para todos os profissionais o banho e curativo são procedimentos estressantes. Para os pacientes a dor é terrivel e não pode ser explicada, mas necessita ser suportada.

UNITERMOS: dor, queimaduras, etnografia

\section{INTRODUÇÃO}

Um trauma térmico sobre a pele produz uma série de alterações locais que irão resultar no aparecimento de dor e também pode provocar alterações definitivas na aparência. Segundo RUSSO (1967), a dor terá início quando houver a excitação direta das terminações nervosas da pele pelo calor, devido a destruição das camadas superficiais da pele e, conseqüentemente, exposição das terminações nervosas sensitivas.

ARTZ et al. (1980) afirmam que "a dor da queimadura está geralmente relacionada com atividades específicas tais como limpeza da ferida, desbridamento, mudança de curativos e fisioterapia”. Por isso, poderá manifestar-se com maior intensidade principalmente na primeira e na segunda fase da queimadura, momentos em que esses procedimentos são realizados com maior intensidade.

O paciente pode reagir à dor de três formas: ignorando-a, reagindo a ela realisticamente ou apresentando uma super reação. $O$ enfermeiro não deve subestimar a dor do paciente em função da reação apresentada, mas sim procurar avaliar e intervir nessa situação (ROBERTS \& PRUITT JR., 1980). A dor pode ser também induzida ou exacerbada pela solidão. Nesse caso, as queixas de dor podem ser um modo de chamar atenção e o paciente pode ser atendido pela presença e pelo toque de um enfermeiro que esteja ao lado dele escutando-o e confortando-o (GOMES et al., 1995). A ansiedade antecipada sobre procedimentos, que podem ou não ser dolorosos, pode causar um aumento progressivo no grau de dor sentida pelo paciente e também provocar insônia, muito freqüente entre pacientes queimados, e pode torná-los menos tolerantes a dor. Sabemos que a tensão muscular relacionada com a apreensão e medo diminuem o limiar da dor.

O grau e a duração da dor que um paciente suporta na trajetória de seu tratamento dependem de fatores como extensão e localização da queimadura, estado emocional, nível de ansiedade e de tolerância à dor, experiências

\footnotetext{
* Professor Doutor do Departamento de Enfermagem Geral e Especializada da Escola de Enfermagem de Ribeirão Preto da Universidade de São Paulo

** Aluna do Curso de Graduação da Escola de Enfermagem de Ribeirão Preto da Universidade de São Paulo, bolsista de iniciação cientifica $-\mathrm{CNPq}$

*** Enfermeiras Encarregadas da Seção de Enfermagem de Queimados do Hospital das Clínicas da Faculdade de Medicina de Ribeirão Preto

***** Professor Titular do Departamento de Enfermagem Geral e Especializada da Escola de Enfermagem de Ribeirão Preto da Universidade de São Paulo
} 
anteriores, cultura e faixa etária. É importante ressaltar que muitos autores, como ARTZ et al. (1980) e GOMES et al. (1995), classificam a dor como física e psicológica. Entretanto, seja a dor física ou psicológica, ela é um problema estreitamente relacionado com a queimadura que deverá ser considerado pelos enfermeiros que trabalham com pacientes queimados. Assim, o enfermeiro deve estar preparado para lidar com a dor do outro e com o fato de que os procedimentos de enfermagem ao serem executados podem potencializar a dor.

A dor, muitas vezes, é considerada pelos profissionais como inerente ao paciente portador de queimaduras. Como afirma RICH (1997), a dor e o sofrimento são vistos como elementos essenciais da condição humana em muitas culturas. Associada a essa crença, está o receio de provocar a dependência do paciente à droga e assim, muitas vezes a dor pode não ser adequadamente tratada.

Neste estudo, partimos do pressuposto de que a dor é uma experiência que depende da cultura aprendida, do significado de uma situação e de outros fatores que são únicos para cada indivíduo (LUDWIG-BEYMER, 1995). ZBOROWSKI (1978) e ZOLA (1966) compararam a interpretação, os significados de dor e outros aspectos da experiência de dor em diversas culturas e concluíram que os diferentes tipos de atitudes, expressões ou comportamentos frente à dor são prescritos pelas diferentes culturas. Neste sentido, a própria imagem corporal do paciente, apresentada ao profissional de enfermagem e percebida pelo próprio paciente após a queimadura pode provocar dor, dependendo das experiências e crenças de ambos. Segundo LUDWIG-BEYMER (1995), o reconhecimento das diferenças culturais, das crenças sobre a dor e sobre o sofrimento pode prevenir muitos enganos ou atitudes inadequadas e assim, conduzir para um cuidado mais efetivo e sensível.

Temos observado que freqüentemente os profissionais da equipe de enfermagem da unidade de queimados do Hospital das Clínicas da Faculdade de Medicina de Ribeirão Preto (HCFMRP), onde este estudo foi desenvolvido, têm dificuldades em lidar com essas situações, pois muitas vezes encontram-se em uma posição que provoca a dor no outro, uma vez que são responsáveis pela realização de procedimentos, como banho e curativos, que são muito dolorosos para os pacientes. Desta forma, os objetivos deste estudo foram: identificar os significados culturais atribuídos pela equipe de enfermagem às manifestações de dor apresentadas pelos pacientes portadores de queimaduras e identificar as percepções dos pacientes frente à dor provocada pela queimadura e à assistência de enfermagem prestada nestas situações.

\section{METODOLOGIA}

Este estudo etnográfico foi orientado pelas propostas de HAMMERSLEY \& ATKINSON (1992). Nessa perspectiva, o investigador busca reconstruir as regras de interpretação e de participação dos sujeitos que interagem em determinados contextos sociais. A etnografia é a descrição de um sistema de significados culturais de um determinado grupo (SPRADLEY, 1980).

Este estudo envolveu uma única situação social e o trabalho de campo foi desenvolvido durante o período de um ano. Apresentamos a seguir, os passos que nortearam este estudo: a escolha da situação social, o trabalho de campo, que envolve as diferentes técnicas de coleta e o registro dos dados, e a análise dos dados.

\section{Escolha da situação social}

A situação social selecionada para o desenvolvimento desse estudo focalizou a assistência de enfermagem à pacientes portadores de queimaduras admitidos na unidade de queimados do HCFMRP. Esta unidade conta com oito leitos, admitindo pacientes adultos e crianças, com período de permanência médio de 45 dias. Possui 15 auxiliares de enfermagem e cinco enfermeiros.

Os profissionais de enfermagem estão em contato permanente com os pacientes, durante as 24 horas do dia. Esses profissionais participam ativamente de todo o processo que envolve a dor em uma unidade de queimados, ora como agentes potencializadores, responsáveis pelos procedimentos que provocam a dor, e ora como agentes que participam do alívio da dor. A dor, tanto da perspectiva de quem sente quanto de quem cuida, é uma experiência que resulta da cultura. Assim, os informantes deste estudo foram os membros da equipe de enfermagem que atuavam nos diferentes turnos de trabalho nessa unidade e os pacientes nela admitidos, no período estudado, que concordaram em participar.

Em um primeiro momento foi necessária a obtenção do consentimento formal do Comitê de Ética e Pesquisa da Instituição, dos profissionais e pacientes envolvidos. Além disso, contamos com o consentimento informal dos profissionais e dos pacientes que participaram do estudo, ou seja, essas pessoas realmente demonstraram interesse e disponibilidade para falar sobre o tema estudado e permitiram a participação dos pesquisadores nas atividades realizadas na unidade. Esses foram os critérios utilizados, a princípio, para inclusão dos participantes no estudo.

A seleção dos informantes a serem entrevistados é um aspecto importante, considerando-se nesse momento, a qualidade das informações que poderão ser obtidas e não a questão da amostragem. Na escolha dos informantes, procuramos também identificar os chamados informanteschave. Nesse aspecto, utilizamos os critérios sugeridos por SPRADLEY (1980) a saber, pessoas que conhecem a sua cultura, que têm um envolvimento atual com esta cultura, 
que têm tempo disponível para fornecer informações e que descrevam a cultura sem fazer análise. Sobre esse último critério, o mesmo autor reconhece que alguns informantes podem assistir o pesquisador na análise das informações, fornecendo uma perspectiva de dentro da cultura. Neste sentido, foi muito importante a participação de dois enfermeiros desta unidade, co-autores deste estudo, no processo de análise dos dados.

\section{Trabalho de campo}

No trabalho de campo, duas técnicas são consideradas fundamentais e foram utilizadas neste estudo: a observação participante e a entrevista. As observações participantes, iniciadas em janeiro de 1998 e concluídas em dezembro do mesmo ano, foram conduzidas pelas seguintes questões orientadoras: o que acontece e como se comportam os auxiliares, enfermeiros e pacientes, em diferentes momentos de cada um dos três turnos de trabalho, diante das manifestações de dor pelos pacientes?

As observações e entrevistas foram realizadas por dois dos pesquisadores que não pertencem ao quadro de profissionais da unidade. Os dados coletados através de observação participante foram registrados em um diário de campo.

A partir de observações participantes foram selecionados 21 informantes: quatro enfermeiros (Enf.), cinco auxiliares de enfermagem (Aux.) e 12 pacientes (Pac.). Estes profissionais foram selecionados considerando as pessoas que, em primeiro lugar, se dispuseram a participar do estudo, que tinham disponibilidade para dar informações e que participavam de atividades que envolviam avaliação e assistência à pacientes portadores de queimaduras. Quanto aos pacientes, também consideramos como critério de seleção: aqueles que se dispuseram a participar do estudo, buscando selecionar diferentes tipos de acidentes, de extensões de áreas queimadas e representantes dos dois sexos. Consideramos também os critérios mencionados anteriormente para a escolha dos informantes-chave.

As entrevistas foram realizadas inicialmente de modo informal, durante as observações participantes, e registradas no diário de campo (Nc.), e a partir da escolha dos informantes, foram realizadas individualmente e registradas com auxílio de gravador. Na realização das entrevistas, duas questões principais foram realizadas aos profissionais e pacientes: Como você percebe e lida com a dor? Como você se sente com relação a dor provocada pela queimadura?

\section{Análise dos dados}

A análise dos dados começou a ser realizada em conjunto com a coleta das primeiras informações. Os dados inicialmente foram organizados em categorias de profissionais, de pacientes e de acordo com a forma como foram coletados: entrevistas com enfermeiros, entrevistas com auxiliares de enfermagem e entrevistas com pacientes (dados resultantes das entrevistas formais) e notas de campo (dados resultantes das observações).

Neste estudo, realizamos esse processo com o auxílio de um programa de computador $O$ Ethnograph, que é capaz de apresentar todo o material considerado relevante para uma categoria em particular, fornecendo um acesso rápido aos dados.

O primeiro passo da análise consistiu em uma leitura cuidadosa dos registros dos dados. Esse procedimento teve como finalidade possibilitar mais um momento de reflexão sobre os dados. Buscamos identificar situações que respondiam aos objetivos do estudo, que causaram surpresa ou perplexidade, e as inconsistências ou divergências entre o que as pessoas ou grupos fizeram ou disseram, com base no que foi relatado, no conhecimento de cada um dos pesquisadores, nas responsabilidades oficiais ou em teorias prévias, de acordo com a proposta de HAMMERSLEY \& ATKINSON (1992).

A partir desse processo, os dados foram codificados, ou seja, informações semelhantes foram agrupadas e rotuladas constituindo unidades de significados que variaram de acordo com os tipos de dados. Este processo foi realizado por cada um dos pesquisadores separadamente, e posteriormente foram comparados os resultados. Não houve divergências neste processo. Após esta organização dos dados, os códigos similares foram agrupados em categorias.

Com a finalidade de procurar as relações entre os conceitos contidos em cada categoria, comparamos cada segmento dos dados, analisando um de cada vez buscando a sua relevância para uma ou mais categorias e comparando os resultados com outros segmentos de forma similar ao proposto por GLASER \& STRAUSS (1967).

\section{RESULTADOS E DISCUSSÃO}

A partir do processo de análise dos dados, foram identificadas as seguintes categorias principais: hora da dor; descrição da dor e lidar com a dor. Com a categorização dos dados, procuramos apreender o tema cultural, ou seja, a conceituação do significado cultural atribuído à dor por pacientes e profissionais de enfermagem. Este tema - a dor da queimadura: terrivel para quem sente, estressante para quem cuida - integra todas as categorias. A seguir, descrevemos, inicialmente, a unidade de queimados em estudo e em seguida, as categorias identificadas neste estudo.

\section{A unidade de queimados em estudo}

$\mathrm{Na}$ unidade de queimados em estudo, os procedimentos de banho e curativo constituem os 
acontecimentos mais importantes. Todas as outras atividades têm alguma relação com esses dois procedimentos. Essas atividades envolvem a participação de um maior contingente de profissionais e esses são os momentos em que a dor está mais presente. $\mathrm{O}$ banho e o curativo são realizados diariamente no período da manhã. Após o desjejum, são verificados os sinais vitais e em seguida, os pacientes são encaminhados para o banho de chuveiro, de turbilhão ou de leito. Antes do banho, algumas vezes, são administrados medicamentos para alívio da dor. As medicações para alivio da dor são prescritas diariamente pelo médico, que escreve na frente da droga, na folha de prescrição, administrar se necessário. A decisão de fazer ou não o medicamento fica a critério do profissional que realiza o procedimento e do próprio paciente. Nessa decisão, estão evolvidos aspectos culturais tanto do ponto de vista de quem cuida quanto de quem sente a dor. Alguns profissionais insistem com o paciente para que aceite o medicamento, outros não chegam a oferecer.

O paciente deambula até o banheiro, em caso de banho de chuveiro, ou até a sala de curativo em caso de banho de turbilhão. No local do banho, as ataduras são retiradas uma a uma. Durante o banho o profissional utiliza uma compressa para auxiliar na limpeza das lesões. Dois tipos de pomadas são mais freqüentemente utilizadas nos curativos: Sulfadiazina de Prata ou Nitro Furazona. Para os pacientes a aplicação da Sulfadiazina de Prata provoca uma sensação de frescor, já a Nitro Furazona, de ardor.

Independentemente do uso da medicação, durante a realização dos procedimentos as manifestações de dor envolvem desde o silêncio até gritos, choro e súplicas para que o sofrimento seja extinguido. As reações da equipe são diferentes dependendo da idade do paciente. Com a criança as reações são de maior tolerância, o que não ocorre com o adulto. Depois da realização dos procedimentos a equipe de enfermagem e os pacientes parecem esgotados. Os profissionais de enfermagem se dirigem para a "sala de café" e geralmente conversam sobre assuntos externos à unidade. Os pacientes permanecem "na sala de recreação" ou em seus quartos e não tem disposição para falar sobre os assunto. Por essa razão, as entrevistas com os pacientes foram realizadas no turno da tarde. No turno da tarde, os paciente assistem televisão e recebem visitas de familiares. Durante o turno da noite os pacientes tentam dormir, mas muitos têm dificuldades e relatam que já estão pensando no curativo do dia seguinte.

\section{A hora da dor}

Todos os profissionais e pacientes apontaram a hora dos procedimentos de banho e curativo como os momentos mais dolorosos para o paciente portador de queimaduras.

No momento do banho, a hora em que a água entra em contato com as lesões foi apontada como muito dolorosa por todos os doze pacientes, como pode ser observado nos depoimentos a seguir:

- Doía na hora do banho, doía muito mesmo e doía na hora de por o curativo. Aquela pomada parecia que queimava... (Entrv. Pac. 1). - Na hora do curativo é triste, quando joga água é terrivel... (Entrv. Pac. 12).

CHOINIERE et al. (1989) examinaram as características da dor em pacientes portadores de queimaduras e concluíram que esses pacientes reportam sentir dor de maior intensidade no momento da realização de procedimentos. Um paciente relatou também a hora da fisioterapia como um momento em que sentia muita dor:

-...é duro também na hora de fazer os exercícios, eu não vejo a hora deste pesadelo acabar (Entrv. Pac. 11).

Um enfermeiro e um paciente também se referiram a um outro momento em que a dor está presente. Para o enfermeiro, durante a noite, o paciente se lembra do acidente, da família e sente dor. Segundo o enfermeiro, um outro tipo de dor. Já para o paciente, durante a noite é muito difícil encontrar uma posição para dormir.

- No banho, no curativo, é nítida a presença da dor fisica, mas durante a noite, quando o paciente fica mais tempo sozinho, torna-se evidente a presença daquela dor que a gente chama de psicológica porque é a hora que ele começa a pensar, que relembra dos fatos, do trabalho, da família, se pergunta "porque eu me queimei...". (Entrv. Enf. 1).

- Dói na hora de dormir, quando a gente não encontra uma posição para se acomodar, qualquer posição dói...(Entrv. Pac. 8).

Para os auxiliares de enfermagem, os procedimentos de banho e curativo são também os mais dolorosos, entretanto são considerados por esses profissionais como procedimentos que devem ser realizados pois irão promover a limpeza das feridas, independente da dor que o paciente possa sentir:

- ...nosso paciente queixa muito de dor, quando a gente expõe a ferida, cai a água e a gente tem que fazer limpeza da ferida... (Entrv. Aux. 8).

A dor também depende da fase da queimadura, esta é uma outra dimensão temporal da dor identificada por um paciente:

- ...dói no banho, no curativo e quando está cicatrizando porque coça bastante, resseca muito a pele. Você tem que ficar hidratando senão dói mais. Quando faz cirurgia é ruim porque também dói bastante principalmente nas áreas doadoras. (Entrv. Pac. 8).

\section{A descrição da dor}

Todos os enfermeiros da unidade descreveram a 
dor como física ou emocional, expressando-se de forma semelhante, quando se referiram aos diferentes tipos de dor, como exemplificado a seguir:

\section{- ...além da dor física tem a dor por tudo o que}

aconteceu, é como se fosse uma dor na alma.

(Entrev. Enf. 3).

Nos deparamos, no dia a dia dessa unidade de queimados, com a dor associada à realização dos procedimentos. Embora a dor manifestada nesses momentos possa parecer inicialmente uma dor unicamente física, quando os pacientes são informados da realização dos procedimentos ou ao menor toque do profissional da enfermagem, já começam a expressar dor intensa e incontrolável.

\section{- ...você acaba de tomar banho hoje e já está pensando no banho do outro dia, de tão traumático que isso é para mim. (Entrev. Pac. 10).}

A divisão da dor em física e emocional pode ser conveniente para os profissionais de saúde diante da necessidade de medicar os pacientes com drogas que podem ser diferentes para cada tipo de dor. Entretanto, segundo MORRIS (1993), a dor é um problema que não pode ser dominado unicamente com o conhecimento sobre uso das drogas, e o hábito de dividi-la em duas categorias pode criar mais sofrimento que alívio. Principalmente quando pensamos que ao fazer um medicamento, o problema da dor já foi resolvido.

Para JACKSON (1992), a descrição da dor como real ou física, ou orgânica, e como irreal ou emocional não é tão simples como a princípio pode parecer. Pode-se pensar que o contraste do real é simplesmente tudo o que é irreal ou seja, a dor irreal seria imaginária, mental, emocional, psicossomática. Entretanto, esses termos têm significados distintos, que podem ser exacerbados quando comparados em diferentes culturas.

Os pacientes também se referiram a diferentes tipos de dor, como exemplificado a seguir:

\section{- Doía na hora do banho (...) quando a água caia, parecia que estava arrancando um pedaço, não era um machucado comum, era diferente (....) Um dia depois do banho, eu me olhei no espelho e fiquei com medo de mim mesma de tão feia que eu estava, aí foi uma dor dentro do coração. (Entrev. - Pac 1).}

Um enfermeiro relatou a manifestação de dor associada à solidão, como pode ser observado no exemplo a seguir:

- Um paciente gritava de dor todas as noites.

Um enfermeiro observou que a dor se manifestava quando seus familiares, que passavam o dia no hospital, iam embora. Este enfermeiro passou a conversar com o paciente após a saída dos familiares. Um dia este paciente observou: "Quando este enfermeiro trabalha a noite, a minha dor melhora sem medicamentos" (Nc).

É importante considerar, como afirma JACKSON (1992), que a dor não é visível; nós inferimos a presença da dor em alguém indiretamente através de observação ou da comunicação do sofrimento, do comportamento da dor. $\mathrm{O}$ comportamento da dor é uma tentativa de comunicar uma experiência que muitas vezes envolve comoção, sofrimento, desmoralização e outros sentimentos ou idéias associadas, o que talvez torne a visão da dor irreal (emocional) separada da dor real (física ) uma tarefa impossível (JACKSON, 1992).

Um paciente, que tentou suicídio, se referiu a uma experiência de dor, associada a um sentimento de culpa ou de desmoralização:

- Já tive a impressão de estar sendo julgado pelas pessoas, cheguei a ouvir eles falarem: "você fez isso agora agüenta". Isso dói tanto quanto a dor da queimadura, essa é a dor que vem de lá de dentro. (Entrev. Pac. 5).

Como afirma MORRIS (1993), a dor é resultado de um processo bioquímico, mas a estória da dor não pode ser contada apenas através deste processo sem incluir toda a subjetividade que a acompanha. Assim como "aprendemos como sentir dor, aprendemos o seu significado". Vários aspectos da cultura estão envolvidos na determinação deste significado como gênero, religião e classe social. Outros aspectos psicológicos e emocionais, também influenciados pela cultura, podem reforçar este significado como a culpa, o medo, raiva, luto e depressão (MORRIS, 1993). A nota de campo a seguir exemplifica esta situação:

- Uma criança do sexo masculino não chorava e não queixava-se de dor durante a realização dos procedimentos. Durante a visita dos familiares, sua mãe sempre insistia: "Homem não chora" (Nc).

Outros pacientes não descreveram a dor considerando dimensões físicas ou emocionais, entretanto eles fizeram algumas afirmações que mostram aspectos da dor. Nos relatos destes pacientes observamos que eles se referiram à reações provocadas pela dor que vão além da expressão de sentimentos tais como náuseas e tremores.

-...é uma dor triste e ardida (...) é horrível, me dá tontura, vontade de vomitar, tremedeira, uma dor que não dá para explicar, é ardida, me dá vontade de chorar. (Entrev. Pac. 4).

- Dor é terrivel (...) é uma dor ardida (...) é só passando por isso para sentir, não tenho como explicar. (Entrev. Pac. 6).

Nos seus depoimentos, os auxiliares de enfermagem não descreveram a dor. Entretanto, todos os auxiliares afirmaram que percebem de forma diferente as manifestações de dor do adulto e da criança e esta percepção 
interfere na forma como lidam com a dor dos pacientes, categoria que descrevemos a seguir.

\section{Lidar com a dor}

Há nos depoimentos dos auxiliares de enfermagem uma preocupação expressa sobre como lidar com a dor, como pode ser observado a seguir.

-...algumas crianças sofrem demais (...) mesmo

que sejam medicadas. Eu vejo isso como muito estressante. (...) Eles sofrem muito e nós também, tenho certeza que muitos colegas meus sentem isso.... (Entrev. Aux. 5).

Para os auxiliares de enfermagem, é mais estressante cuidar de crianças e é difícil fazer os procedimentos de banho e curativo. Para eles, esses procedimentos têm que ser feitos e sempre irão causar dor. A manifestação de dor pelos pacientes, principalmente pelas crianças, causa estresse entre todos os que participam do curativo e estas manifestações são compreensíveis. Entretanto, para os auxiliares os pacientes adultos deveriam suportar a dor, possivelmente porque fazer esses procedimentos é mais estressante quando há manifestações de dor através de choros e gritos. Essa percepção não se aplica as crianças que quando não choram provocam mais estresse ao profissional.

— ...eles (os pacientes) expressam a dor chorando, através de gestos, expressão facial, gritando, principalmente na hora do banho (...) As crianças deixam a gente mais sensivel, agora $o$ adulto não! Porque a gente acha que o adulto tem que suportar a dor, pelo fato de que eles entendem melhor as coisas que as crianças... (Entrev. Aux. 1).

-É dificil ver qualquer paciente sentindo dor.... Eu acho mais dificil lidar com a dor da criança. Se ela não chorar é mais dificil, porque parece que ela não está pondo para fora de verdade aquilo que está sentindo. (...) Quando vejo algum adulto chorando, eu penso: "ele não consegue se controlar", eu vejo por mim, quando eu sinto uma dor, eu tento me controlar e aqui têm uns pacientes que não são assim, eles extrapolam, xingam, fazem aquele escândalo todo, é aquela coisa descontrolada. Já na criança quando ela fala que está sentindo dor está mesmo. (Entrev. Aux. 1).

Lidar com a dor para os auxiliares de enfermagem é uma situação estressante, mas ao mesmo tempo há procedimentos, dar o banho e fazer o curativo, que se traduzem em tarefas ou missões que devem ser cumpridas. Estes procedimentos fatalmente envolvem dor e a dor é tanta que, na percepção dos auxiliares, não adiantam os medicamentos.
- ...é pior deixar o paciente sair do banho do jeito que entrou. Eu não consigo fazer ele parar de sentir dor, mas eu sei que a minha missão foi cumprida para ajudá-lo (Entrev. Aux. 1).

- ...mas você tem que limpar. Mas aquilo vai doer mesmo, independente de você arrumar uma fórmula para diminuir a dor... (Entrev. Aux. 1).

Nos depoimentos dos enfermeiros, observa-se também as dificuldades em lidar com a dor, principalmente quando os pacientes são crianças.

Assim como os auxiliares de enfermagem, os enfermeiros e pacientes também consideram que os medicamentos não adiantam:

- ...eles dão remédio para gente, mas nada passa é aquela dor sem fim... (Entrv. Pac. 10).

- ...e ele foi medicado mais ainda refere que está com dor (...) A única coisa a fazer é dizer que não têm condições (...) não é a gente que comanda (Entrev. Aux. 6).

As dosagens e as medicações administradas antes dos procedimentos parecem não resolver o problema da dor, mas provavelmente fornecem algum alívio, sem alterar muito o nível de consciência destes pacientes que participam da realização do procedimento. Entretanto, para os pacientes, estes medicamentos não aliviam a dor. Manter os pacientes despertos durante a realização dos procedimentos terapêuticos pode ter vantagens para o pacientes e para os profissionais que realizam os curativos, entretanto pode também ser muito traumático para ambos.

A ausência de um tratamento adequado para a dor durante o período de internação de pacientes portadores de queimaduras, além de ser uma experiência traumática do ponto de vista psicológico, contribui para a presença de subseqüentes problemas físicos (BLUMENFIELD \& SCHOEPS, 1992). Esses pacientes necessitam realizar uma grande quantidade de atividades de fisioterapia que exigirão um desempenho máximo que poderá não ser alcançado quando não há controle sobre a dor.

Uma outra forma de lidar com a dor é associá-la ao processo de cicatrização das lesões:

— ...eu sei que é bom eu sentir esta dor, porque

sei que vai cicatrizar.(Entrev. Pac. 4).

Muitas vezes, os profissionais tentam explicar a dor de uma ferida dizendo aos pacientes que se dói é porque o tecido está vivo. Segundo PERRY (1984), que estudou a dor em um serviço de queimados, nestas unidades em que o desfiguramento provocado pelo trauma e em que os procedimentos ameaçam esgotar a vida dos pacientes, a dor serve para ambos, pacientes e equipe, para manutenção da confiança de que o paciente está vivo. Assim, é como se a dor fizesse parte do processo de tratamento. Ter que controlar e suportar a dor significa ser herói, significa ser respeitado e aceito num ambiente de uma unidade de queimados, um ambiente em que o paciente parece estar predestinado ao sofrimento: 
- ... a gente tem que suportar sem fazer escândalo, gritar (...) eu tinha que suportar aquilo... As vezes eu estava bem quietinho, ai chegava o pessoal de enfermagem e era hora do banho, nossa que tristeza eu tinha de agüentar aquilo.(...) Quando cheguei aqui, o pessoal dizia até que eu era herói em não reclamar. Porque não adianta, eles tem que fazer o serviço, quem estava precisando de cuidado era eu, eu tinha que suportar aquilo. Está doendo? Está! Vai tirar o curativo? Tira! (Entrev. Pac.6)

O paciente descobre então que o procedimento será realizado de qualquer forma e questiona a forma como é feito. Recorre a autoridade máxima da unidade: o médico; mas percebe que não resolve, só resta então recorrer a Deus:

— ...aquela dor sem fim não dá para agüentar, quando tem que esfregar os machucados, eles esfregam muito. (...) Não adianta falar, eles querem é lavar, dá vontade de sair correndo na hora que eles passam aquele paninho. Eujá falei com o médico e ele disse que é desse jeito mesmo, pedi para ele me dar uma injeção aqui no braço queimado, ele disse que não tem jeito, então o jeito é agüentar. Agora vai fazer cirurgia no braço e então eu quero ver. É só Deus para me ajudar. (Entrev. Pac.1).

No depoimento desta auxiliar de enfermagem observa-se que ela também recorre a Deus para poder cumprir a sua tarefa de realizar o procedimento:

— Às vezes me pego rezando no meio de um curativo quando ele é dificil, mas certamente me sentiria pior se não fizesse o que tenho de fazer.. (Entrev. Aux. 1).

A dor é então sentida e deve ser suportada tanto pelos profissionais que cuidam, quanto pelos pacientes que são dia após dia submetidos a ela, principalmente nos momentos de banho e curativo. Como disse um enfermeiro, cada um sente dor de um jeito:

\section{- ... dependendo do paciente, parece que a dor está passando para mim, meu estômago começa doer. (...) Fico às vezes angustiada (...) Cada um sente a dor de um jeito. (Entrev. Enf. 1).}

Estes profissionais, expressam sentimentos de impotência diante de uma situação que, segundo eles, não se modificam com o decorrer do tempo, mas apesar da dificuldade de lidar com a dor dos pacientes, eles reconheceram a necessidade de buscar outras alternativas para enfrentar essa situação:

\footnotetext{
- Alguns dizem que a gente se acostuma, eu acho que isso não existe, ninguém se acostuma com a dor... (Entrev. Aux. 1).

- Precisaríamos de mais retaguarda para poder enfrentar. (...) A gente tenta trabalhar isso, estar perto do paciente, tentando aliviar, mas ainda
}

tem que aprender muita coisa. (Entrev. Enf. 3).

O significado da dor da queimadura para profissionais e pacientes: terrível para quem sente, estressante para quem cuida

O tema cultural que emergiu dos dados, a dor $d a$ queimadura: terrivel para quem sente, estressante para quem cuida, integra todas as categorias. A análise do significado atribuído à dor, a partir da interpretação dos depoimentos dos profissionais e dos pacientes desta unidade de queimados, indica que a dor provoca estresse nos que cuidam e é percebida como terrível pelos pacientes durante todo o período de internação.

Os enfermeiros consideram a dor como física e emocional; os auxiliares enfatizam a necessidade de os adultos controlarem as manifestações de dor, os pacientes mostram nos depoimentos o quão terrível é a dor da queimadura. Para ambos, profissionais de enfermagem e pacientes, um ponto comum é a dificuldade de lidar com a dor.

A perspectiva de todos os enfermeiros sobre a divisão da dor em física e emocional pode ser entendida pois, como afirma MORRIS (1993), atualmente em muitas culturas, as pessoas acreditam que a dor pode ser dividida em dois tipos: física e mental. Para esse autor, essa crença é um mito e como todo mito cumpre o seu papel social de preservar uma porção verdadeira e esconder aquilo que não conseguimos explicar e que, deste modo, não conseguimos resolver. Assim, a percepção da dor não pode ser definida simplesmente em termos de condução de tipos de estímulos particulares, mas sim como uma experiência individual que depende da aprendizagem do significado cultural de uma situação e de outros fatores que são únicos e individuais (LUDWING-BEYMER, 1995).

A expectativa dos auxiliares de enfermagem de que os pacientes adultos controlem as manifestações de dor pode ser explicada através da natureza das atividades de enfermagem com esses pacientes, que implica no controle dos sentimentos daqueles que executam e assim, esperam o mesmo comportamento de outras pessoas. Para LUDWINGBEYMER (1995), em parte como resultado de uma subcultura da enfermagem, os enfermeiros freqüentemente esperam que as pessoas sejam objetivas e que relatem com detalhes a sua experiência da dor, mas demostrem pouca respostas emocionais como choros e gritos.

As diferenças culturais na percepção da dor podem contribuir para que a dor seja subestimada e seja também assistida deste modo. Ao reforçamos os comportamentos contidos em relação a manifestação da dor, estamos estimulando que os pacientes reajam desta forma, assumindo, como disse um paciente, o comportamento de um herói que, como não manifesta a dor, pode não ser medicado adequadamente e ainda, servir de exemplo na escolha da medicação de outros pacientes. Neste contexto, pacientes que se queixam, choram e gritam como 
manifestação de dor, muitas vezes, são considerados como aqueles que extrapolam e fazem escândalo, como mencionou um auxiliar de enfermagem. Assim, estes aspectos culturais da interpretação da dor podem influenciar sua avaliação.

Os pacientes descreveram a dor da queimadura como uma coisa terrível e inexplicável, que não melhora com os medicamentos administrados, o que pode indicar que a dor nesta Unidade, por influência da cultura, esteja sendo subestimada ou uma inadequação da terapêutica adotada, ou ambos. BLUMENFIELD \& SCHOEPS (1992) sugerem que programas educativos, relacionados com o tratamento da dor, sejam organizados para equipe de profissionais, pacientes e familiares.

A manifestação de dor pelos pacientes provoca estresse nos profissionais; assim, para essas pessoas é menos traumático realizar o procedimento quando o paciente aceita a dor. A expectativa de que o paciente suporte a dor é também observada quando a queimadura decorre de uma autoagressão ou de comportamentos que são culturalmente reprováveis. Essa é uma forma de enfrentamento utilizada pelos profissionais de enfermagem que decorre de um julgamento e envolve a consideração de valores e crenças, e que implica na necessidade do paciente suportar a dor. Os profissionais de enfermagem precisam compreender como afirma LUDWING-BEYMER (1995), que a dor é uma experiência pessoal influenciada pela cultura e a compreensão dessa cultura é crítica quando assistimos pessoas com dor. A compreensão das diferenças culturais e a não imposição de crenças e valores são aspectos essenciais da conduta do profissional de enfermagem na realização do cuidado. Torna-se assim importante a compreensão da cultura da pessoa com dor e da própria cultura pelos que cuidam. Desta forma, outras formas de enfrentamento devem ser apresentadas aos profissionais e nesse sentido, grupos de apoio podem ser uma alternativa que, além de propiciar momentos de discussão sobre o problema e permitir que eles busquem outras formas de enfrentamento de estresse, constituem um momento de educação continuada da equipe.

\section{BURN PAIN: TERRIBLE FOR THE ONES WHO FEEL, STRESSFUL FOR THE ONES WHO CARE}

The goals of the study were to understand the cultural meaning that the nursing team and burn patients attribute to burn pain. Participant observations were carried out during one year at a Burn Unit. Semi-structured interviews with four nurses, five nursing auxiliaries and 12 patients were recorded. The burn pain is understood by nurses as physical and emotional pain. For professionals and patients, bath and dressing changes are stressful. For patients, burn pain is terrible and they can not explain it. However, they feel they should hold it up.

KEY WORDS: pain, burns, ethnography

\section{EL DOLOR DE LA QUEMADURA: TERRIBLE PARA QUIEN SIENTE ESTRESANTE PARA QUIEN CUIDA}

Los objetivos de este estudio fueron identificar los significados culturales que el equipo de enfermería atribuye a las manifestaciones de dolor expresadas por los pacientes portadores de quemadura e identificar las percepciones de los mismos frente al dolor provocado por la quemadura y la atención de enfermería prestada en estas condiciones. Fueron realizadas observaciones participantes y entrevistados cuatro enfermeros, cinco auxiliares y 12 pacientes en una Unidad de Quemados. El dolor de la quemadura fue comprendido por los enfermeros como: física y emocional. Para todos los profesionales y pacientes el baño y la curación son procedimientos estresantes. Para los pacientes el dolor es terrible y no consiguen explicarlo, pero deben soportarlo.

TÉRMINOS CLAVES: dolor, quemaduras, etnografia

\section{REFERÊNCIAS BIBLIOGRÁFICAS}

01. ARTZ, C.P.; MONCRIEF, J.A.; PRUIT, B.A. Queimaduras. Rio de Janeiro: Interamericana, 1980.

02. BLUMENFIELD, M.; SCHOEPS, S. Reintegrating the healed burned adult into society: psychological problems and solutions. Clin. Plastic Surg., v. 19, n.
3, p. 599-605, 1992.

03. CHOINIERE, M.; MELZALK, R.; RODEAU, J.; GIRARD, N.; PAQUIN, M.J. The pain of burns: characteristics and correlates. J. Trauma, v. 29, n. 11, p. 1531-9, 1989.

04. GLASER, B.G.; STRAUSS, A.L. The discovery of grounded theory: strategies for qualitative research. New York: Aldine Publisher, 1967.

05. GOMES, D. R.; SERRA, M .C. ; PELLON, M. Queimaduras. Rio de Janeiro: Revinter, 1995. 
06. HAMMERSLEY, M.; ATKINSON, P. Ethnography: principles in practice. 7. ed. London: Routledge, 1992.

07. JACKSON, J.E. After a while no one believes you: real and unreal pain. In: GOOD, M.D.; BRODWIN, P.E.; GOOD, B.J.; KLEINMAM, A. Pain as human experience an anthropological perspective. Los Angeles: University of California Press, 1992.p. 138168.

08. LUDWIG-BEYMER, P. Transcultural aspects of pain. In: ANDREWS, M.M.; BOYLE, J.S. Transcultural concepts in nursing care. 2. ed. Philadelphia: Lippincott, 1995. p. 301-21.

09. MORRIS, D. The culture of pain. Los Angeles: University of California Press, 1993.

10. PERRY, S.W. Undermedication for pain on a burn unit. Gen. Hosp. Psychiatry, v. 6, n. 4, p. 308-16, 1984.
11. RICH, B.A. A legacy of silence: bioethics and the culture of pain. J. Med. Human., v. 18, n. 4, p. 233-59, 1997.

12. ROBERTS, M.L.; PRUITT JR., B.A. Cuidados de enfermagem e considerações psicológicas. In: ARTZ, C.P.; MONCRIEF, J.A.; PRUIT, B.A. Queimaduras. Rio de Janeiro: Interamericana, 1980.

13. RUSSO, A.C. Tratamento das queimaduras. São Paulo: Savier, 1967.

14. SPRADLEY, J.P. Participant observation. Orlando: Holt, Rinehart, Winston, 1980.

15. ZBOROWSK, M. Cultural components in responses to pain In: LOGAN, M. H.; HUNT, E.E.J. Health and the human condition: perspectives on medical anthropology. Massachusetts: Duxbury Press, 1978. p. 281-93.

16. ZOLA, I.K. Culture and syntoms: an analysis of patients' presenting complaints. Am. Sociol. Rev., v. 31, p. 61530, 1966. 